Journal of Animal and Veterinary Advances 11 (11): 1774-1779, 2012

ISSN: $1680-5593$

(C) Medwell Journals, 2012

\title{
Effect of Physical Form of Diet and Frequency of Feeding on Digesta Retention Time and Digestion in Najdi Lambs
}

\author{
${ }^{1}$ Mohamed A. Abouheif, ${ }^{1}$ Mohamed Y. Al-Saiady, ${ }^{1}$ Saud I. Al-Mufarrej, \\ ${ }^{2}$ Aziz Makkawi, ${ }^{3} \mathrm{Hafiz}$ A. Ibrahim and ${ }^{1}$ Riyadh S. Aljumaah \\ ${ }^{1}$ Department of Animal Production, College of Food and Agricultural Sciences, \\ P.O. Box 2460, King Saud University, 11451 Riyadh, Saudi Arabia \\ ${ }^{2}$ Department of Animal Production, College of Agricultural Studies, \\ Sudan University of Science and Technology, Khartoum, Sudan \\ ${ }^{3}$ Department of Nutrition and Technical Services, ARASCO Research, \\ P.O. Box 53845, 11593 Riyadh, Saudi Arabia
}

\begin{abstract}
Twenty four Najdi ram lambs, weighing an average of $42.0+0.6 \mathrm{~kg}$ were utilized in this experiment to evaluate the effects of various alfalfa hay particle lengths in the diets and frequency of feeding on nutrients digestibility, ruminal retention time, total mean retention time and transit time. Lambs were randomly placed in a $3 \times 2$ factorial arrangement of three dietary treatments: 9.5 and $14 \mathrm{~mm}$ diets where alfalfa hay was processed to 9.5 and $14 \mathrm{~mm}$ particle lengths, respectively mixed with 3 parts of concentrate and pelleted as total mixed ration and long hay diet where one part of loose alfalfa hay $(17.8 \pm 2.4 \mathrm{~cm})$ was offered in combination with 3 parts of only-concentrate pellet and two feeding frequencies: once daily feeding at $0800 \mathrm{~h}$ and twice daily feeding in two equal portions at 0800 and $1500 \mathrm{~h}$. All dietary treatments were homogeneous in their ingredient composition. Altering the particle length of alfalfa hay in diets did not affect the digestibility of DM or CP whereas digestibilities of $\mathrm{ADF}$ and NDF and ruminal retention time were 4.2 and $5.3 \%$ units higher $(\mathrm{p}<0.05)$ and $6.3 \mathrm{~h}$ longer $(\mathrm{p}<0.05$ ), respectively for the long hay diet versus the $9.5 \mathrm{~mm}$ pelleted diet. The total mean retention time for the long hay diet was longer $(\mathrm{p}<0.05)$ at $63.1 \mathrm{~h}$ compared with the 9.5 and $14 \mathrm{~mm}$ diets. Lambs fed once a day had higher $(\mathrm{p}<0.05) \mathrm{NDF}$ digestibility and 4.9 and $3.8 \mathrm{~h}$ longer $(\mathrm{p}<0.05)$ ruminal and total mean retention times, respectively than lambs fed twice daily. On the other hand, neither particle length of the alfalfa hay nor frequency of feeding had affected $(\mathrm{p}>0.05)$ the lower tract retention time and transit time.
\end{abstract}

Key words: Particle length, feeding frequency, retention time, digestibility, transit time

\section{INTRODUCTION}

Complete pelleted diets are increasing in popularity on many sheep farms in Saudi Arabia. Particle size of roughage component of a complete pelleted diet, plane of nutrition at which the diet is fed and feeding schedules have been shown to govern the rate of digesta outflow from the rumen thereby influencing the control of feed intake, energy utilization and digestibility (Hadjigeorgiou et al., 2003; Robles et al., 2007).

Several researchers indicated that reduction of forage particles given separately in long form and in combination with other feeds or ground in a complete pelleted diet resulted in an increased rate of passage from the rumen (Welch, 1982; Leonardi et al., 2005) and decreased DM and fiber digestibility (Hadjigeorgiou et al., 2003). On the other hand, ruminal passage rates in ruminant
(Shaver et al., 1986; Krause et al., 2002) and nutrients digestibility within the alimentary tract of sheep (Hogan and Weston, 1967; Thomson et al., 1972) were unaffected by chop length or processing treatments. Experiments conducted with various classes of ruminants to evaluate the influences of different feeding schedules on digestibility and digesta outflow from the rumen have yielded conflicting results. Ulyatt et al. (1984) and Robles et al. (2007) showed that feeding schedules in which small meals are offered at more frequent daily intervals tend to increase the rate of ingesta removal from the rumen resulting in greater escape of potentially degradable substrate. On the other hand, Goetsch and Galyean (1983) and Klusmeyer et al. (1990) reported no effects of feeding frequency on ruminal outflow in cows. The objective of the present study was to evaluate and compare the influence of feeding two particle lengths

Corresponding Author: Mohamed A. Abouheif, Department of Animal Production, College of Food and Agricultural Sciences, P.O. Box 2460, King Saud University, 11451 Riyadh, Saudi Arabia 
(9.5 and $14 \mathrm{~mm}$ ) of alfalfa hay in pelleted complete diets and long alfalfa hay in combination with a pelleted only-concentrate diet either once or twice daily on digesta kinetics in growing Najdi lambs.

\section{MATERIALS AND METHODS}

Animals and preparation of diets: Twenty four Najdi male lambs of average body weight $42.0 \pm 0.6 \mathrm{~kg}$ were used in this experiment to evaluate the effects of particle length of alfalfa hay and frequency of daily feeding on nutrient digestibility and digesta retention times. Lambs were individually weighed, identified, vaccinated, injected against internal and external parasites and vitamin A-D-E injections were given. All lambs were assigned randomly to one of six equal groups in a $3 \times 2$ factorial arrangement of three alfalfa hay particle lengths $(9.5$ and $14 \mathrm{~mm}$ pelleted diets and long hay diet) and two feeding frequencies (feeding once or twice daily). Thereafter, lambs were individually confined in false-bottom metabolic crates to facilitate separate collection of total feces.

All experimental diets utilized in this study were homogeneous in their ingredient composition with the only variable being the particle length of the alfalfa hay used in each diet (Table 1). All diets were formulated to meet daily energy and protein requirements (NRC, 1985). A single batch of alfalfa hay was processed to yield three particle lengths: 9.5 and $14 \mathrm{~mm}$ and long hay.

Table 1: Ingredient $\mathrm{s}^{1}$ and chemical composition of the experimental diets

\begin{tabular}{|c|c|c|c|}
\hline \multirow{2}{*}{\multicolumn{4}{|c|}{$\frac{\text { Items }}{\text { Ingr edient }}$}} \\
\hline & & & \\
\hline \multicolumn{2}{|l|}{ Alfalfa hay } & 25.00 & - \\
\hline \multicolumn{2}{|l|}{ Barley } & 59.44 & 79.25 \\
\hline \multicolumn{2}{|l|}{ Wheat bran } & 7.50 & 10.00 \\
\hline \multicolumn{2}{|l|}{ Soybean meal } & 2.94 & 3.92 \\
\hline \multicolumn{2}{|l|}{ Salt } & 0.38 & 0.51 \\
\hline \multicolumn{2}{|l|}{ Limestone } & 1.73 & 2.31 \\
\hline \multicolumn{2}{|l|}{ Acid buf ${ }^{2}$} & 0.38 & 0.51 \\
\hline \multicolumn{2}{|l|}{ Molasses } & 2.25 & 3.00 \\
\hline \multicolumn{2}{|l|}{ Lignobond $^{3}$} & 0.23 & 0.30 \\
\hline \multicolumn{2}{|l|}{ Trace minerals and vitamin ${ }^{4}$} & 0.15 & 0.20 \\
\hline \multicolumn{2}{|l|}{ ME Mcal.kg ${ }^{-1} \mathrm{DM}^{5}$} & 2.78 & 3.06 \\
\hline Chemical composition & $9.5 \mathrm{~mm}^{6}$ & $14 \mathrm{~mm}^{6}$ & Long hay? \\
\hline $\mathrm{DM}$ & 95.68 & 95.87 & 95.35 \\
\hline $\mathrm{CP}$ & 14.53 & 14.43 & 13.92 \\
\hline $\mathrm{EE}$ & 1.16 & 1.16 & 0.83 \\
\hline $\mathrm{ADF}$ & 24.91 & 24.55 & 28.29 \\
\hline NDF & 14.22 & 14.77 & 16.96 \\
\hline Ash & 7.46 & 7.23 & 6.92 \\
\hline
\end{tabular}

${ }^{1}$ TMR = Pelleted Total-Mixed Ration; Concentrate = Pelleted onlyconcentrate; DM basis, $\%$; ${ }^{2}$ Natural buffer derived from seaweed (CelticSea Company, Ireland); ${ }^{3} \mathrm{Calcium}$ lignosulfate as pellet binder; ${ }^{4} \mathrm{Contained}$ $10,000\left(\mathrm{IU} \mathrm{kg}{ }^{-1}\right.$ ) Vitamin $\mathrm{A}, 1000\left(\mathrm{IU} \mathrm{kg}{ }^{-1}\right.$ ) Vitamin D, $20\left(\mathrm{IU} \mathrm{kg}^{-1}\right.$ ) Vitamin E, $300 \mathrm{mg} \mathrm{kg}{ }^{-1}$ of $\mathrm{Mg}, 24 \mathrm{mg} \mathrm{kg}^{-1}$ of Cu, $0.6 \mathrm{mg} \mathrm{kg}^{-1}$ of Co, $1.2 \mathrm{mg} \mathrm{kg}^{-1}$ of $\mathrm{I}, 60 \mathrm{mg} \mathrm{kg}-1$ of $\mathrm{Mn}, 0.3 \mathrm{mg} \mathrm{kg}-1$ of $\mathrm{Se}$ and $60 \mathrm{mg} \mathrm{kg}{ }^{-1}$ of $\mathrm{Zn}$ of finished feed; ${ }^{5}$ Tabulated; ${ }^{6} \mathrm{Alfalfa}$ hay was chopped to either 9.5 or $14 \mathrm{~mm}$ lengths and incorporated into pelleted TMR; ${ }^{7}$ Loose alfalfa hay with an average length of $17.8 \mathrm{~cm}$ was mixed with pelleted only-concentrate in a ratio of $1: 3$, respectively
The 9.5 and $14 \mathrm{~mm}$ particle lengths were prepared by feeding the hay through, a chopper machine equipped with 9.5 and $14 \mathrm{~mm}$ screens, respectively whereas the long hay was used directly from the bale without any processing. The average length of long hay stems was $17.8 \pm 2.4 \mathrm{~cm}$ (ranged from $8.4-25.6 \mathrm{~cm}$ ). A master batch of all dietary concentrate ingredients was ground through a $4.76 \mathrm{~mm}$ screen, mixed thoroughly in a stainless steel vertical mixer and divided into three equal portions to be mixed subsequently with the hay of the designated particle length.

Diets 9.5 and $14 \mathrm{~mm}$ were prepared as pelleted total-mixed rations, each with a ratio of concentrate ingredient to alfalfa hay of 3:1 (DM basis); the mixed ingredients were put directly into the pelleting unit in front of the hammer mill. Steam was used to enhance the process of pelleting. The concentrate ingredients used with the long hay diet were pelleted without mixing with hay to form only-concentrate pellets (Table 1). All pellets retained their stability throughout the experiments.

Feeding protocol: Lambs fed 9.5 and $14 \mathrm{~mm}$ pelleted diets were offered a sufficient quantity of daily feed (95 g DM.day ${ }^{-1} \cdot \mathrm{w}^{0.75}$ ) to resemble ad libitum consumption with $5 \%$ refusals whereas lambs fed long hay diet were offered 23.7 g DM.day ${ }^{-1} \cdot \mathrm{w}^{0.75}$ long alfalfa hay plus 71.3 g DM.day ${ }^{-1} . \mathrm{w}^{0.75}$ of only-concentrate pellets. To maintain a ratio of hay intake in the long hay diet equivalent to $25 \%$ of the ration, offering of onlyconcentrate pellet was withheld to cause the lamb to consume the entire long hay portion. For each diet, the feeding protocol involved once daily feeding at $0800 \mathrm{~h}$ and twice daily feeding in two equal portions at 0800 and $1500 \mathrm{~h}$ resembling two feeding frequencies. Refusals were removed daily before the morning meal, weighed, sampled for DM determination and then discarded.

Digestibility and digesta retention times: The digestibility trial lasted for 30 days ( 21 days adaptation followed by 9 days of feces collection). During the 1st 5 days of the collection period (digestibility trial), daily feed intake and total output of feces were recorded and a $10 \%$ aliquot of voided feces was dried at $65^{\circ} \mathrm{C}$ for $24 \mathrm{~h}$. The dried samples were ground through a $1 \mathrm{~mm}$ screen and stored for later analyses. Samples of the experimental diets and feces were analyzed for DM and crude protein according to AOAC (1995). ADF and NDF were determined according to Van Soest et al. (1991).

On the morning of day 6 of the collection period, $2 \mathrm{~g}$ of $\mathrm{Cr}_{2} \mathrm{O}_{3}$ was mixed by hand to each feed allotment of each lamb. Feces voided were collected at $0,6,12,18,24,30,36$, $42,48,54,60,66,72,84$ and $96 \mathrm{~h}$ post-adding the $\mathrm{Cr}_{2} \mathrm{O}_{3}$ to 
the morning meal; the fecal samples were dried at $65^{\circ} \mathrm{C}$ for $24 \mathrm{~h}$. Dried fecal samples were mixed thoroughly with an acid mixture to transform feces into a solution for chromium content measurement using a spectrophotometer method (Liu et al., 2005). Fecal $\mathrm{Cr}^{+3}$ excretions curve was fitted to the doublecompartment model represented by the two exponential constants and a time delay (Dhanoa et al., 1985):

Where:

$$
\mathrm{Y}=\mathrm{A} \mathrm{e}^{-\mathrm{k1}(\mathrm{t}-\mathrm{TT})}-\mathrm{Ae}^{-\mathrm{k} 2(\mathrm{t}-\mathrm{TT})}
$$

$\mathrm{Y}=$ Marker concentration in the feces at time $\mathrm{t}$

$\mathrm{A}=$ Biologically undefined scale parameter

$\mathrm{k} 1=$ Ruminal rate of passage $(\% / \mathrm{h})$

$\mathrm{k} 2=$ Lower digestive tract rate of passage $(\% / \mathrm{h})$

$\mathrm{t} \quad=$ Sampling time post dosing $(\mathrm{h})$

$\mathrm{TT}=$ Time of first appearance of marker in the feces or transit time

Total mean retention time in the digestive tract was calculated as the sum of retention in the rumen $(1 / \mathrm{k} 1)$ and in the lower digestive tract $(1 / \mathrm{k} 2)$ plus the Transit Time (TT). Data were calculated by nonlinear regression using the NLIN (Iterative Marquardt Method) procedures (SAS, 1998). Data for nutrient composition, apparent digestibility coefficients and various retention times and transit time were statistically analyzed by ANOVA using GLM procedures of SAS (1998). A significance level of 5\% was used to express statistical difference between means.

\section{RESULTS AND DISCUSSION}

Digesta retention times: Because of no interactions were detected, data are presented for main effects. Data describing percent chromic oxide recovery, transit time and retention times by growing Najdi ram lambs fed diets containing alfalfa hay varying in particle lengths either once or twice daily are shown in Table 2. Recovery of $\mathrm{Cr}^{+3}$ in the feces was $>85 \%$ for all experimental diets which coincided well with the findings by Utley et al. (1970) and De Oliveira et al. (2007) who had obtained good recoveries using $\mathrm{Cr}_{2} \mathrm{O}_{3}$ as a powder. The recovery of $\mathrm{Cr}^{+3}$ in the feces did not differ by alfalfa hay chopping length and frequency of daily feeding. The description of the $\mathrm{Cr}^{+3}$ excretion patterns in the fecal material by using the Two-compartment Exponential model (Dhanoa et al., 1985) resulted in reasonable $R^{2}$ values ranging between 0.774 and 0.854 . Residence time of feed particles in the rumen was indicated as a factor regulating extent of digestion (Alwash and Thomas, 1971), feeds passing at a slower rate from the rumen allowed more time for microbial breakdown. In this study, there was significant $(\mathrm{p}<0.05)$ effect of the particle length on ruminal retention time; lambs fed on 9.5 and $14 \mathrm{~mm}$ pelleted diets had shorter ruminal retention time than those fed on long hay diet. Particle size and functional specific gravity are critical feed characteristics that influence rate of passage from the rumen (Kaske and van Engelhardt, 1990). Reduction of particle size of forage by grinding or pelleting resulted in an increased rate of passage of particulate matter from the rumen (Welch, 1982; Leonardi et al., 2005). In a conclusion, the larger particles probably required a longer rumination time to reduce digesta particle size so passage out of the rumen could occur.

Second compartment retention time (assumed to be the lower digestive tract) and transit time were not significantly ( $p>0.05)$ different between various studied particle length diets. The total mean retention time for the long hay diet was longer $(\mathrm{p}<0.05)$ at $63.1 \mathrm{~h}$ compared with the other two pelleted diets which ranged from $55.6 \mathrm{~h}$ for the $9.5 \mathrm{~mm}$ diet to $57.5 \mathrm{~h}$ for the $14 \mathrm{~mm}$ diet. Similar patterns were obtained by Hadjigeorgiou et al. (2003) who found that total mean retention time in sheep declined significantly $(\mathrm{p}<0.05)$ with the reduction in hay staple

Table 2: The effect of particle length of alfalfa hay and frequency of feeding on digesta retention times and nutrient digestibility coefficients (\%) in growing

\begin{tabular}{|c|c|c|c|c|c|c|}
\hline \multirow[b]{2}{*}{ Characters } & \multicolumn{3}{|c|}{ Particle length } & \multicolumn{3}{|c|}{ Feeding frequency } \\
\hline & $9.5 \mathrm{~mm}$ & $14 \mathrm{~mm}$ & Long hay & Once/day & Twice/day & SEM \\
\hline \multicolumn{7}{|l|}{ Digesta retention times } \\
\hline Chromium recovery (\%) & 90.300 & 85.300 & 87.800 & 88.100 & 87.400 & 4.05 \\
\hline Ruminal retention (h) & $33.700^{b}$ & $35.100^{b}$ & $40.000^{\mathrm{a}}$ & $38.700^{\mathrm{a}}$ & $33.800^{b}$ & 3.15 \\
\hline Lower tract retention (h) & 12.200 & 12.800 & 12.900 & 11.800 & 13.400 & 1.66 \\
\hline Transit time (h) & 9.700 & 10.600 & 10.100 & 10.500 & 9.700 & 0.84 \\
\hline Total mean retention (h) & $55.600^{b}$ & $57.500^{b}$ & $63.100^{\mathrm{a}}$ & $60.900^{\mathrm{a}}$ & $57.100^{b}$ & 4.66 \\
\hline $\mathrm{R}^{2}$ & 0.780 & 0.774 & 0.807 & 0.854 & 0.789 & - \\
\hline \multicolumn{7}{|l|}{ Digestibility coefficients } \\
\hline $\mathrm{DM}$ & 77.300 & 76.800 & 78.100 & 76.400 & 77.300 & 1.70 \\
\hline $\mathrm{CP}$ & 82.600 & 83.100 & 83.700 & 83.100 & 83.600 & 1.18 \\
\hline $\mathrm{ADF}$ & $45.600^{b}$ & $46.100^{\mathrm{ab}}$ & $49.800^{\mathrm{a}}$ & 47.200 & 48.400 & 2.51 \\
\hline NDF & $48.100^{b}$ & $47.600^{b}$ & $53.400^{\mathrm{a}}$ & $51.300^{\mathrm{a}}$ & $47.000^{b}$ & 2.09 \\
\hline
\end{tabular}


length. These researchers have reported mean retention time ranging from $45.9-54.6 \mathrm{~h}$ for chopped hay varying in length from $0.69-13.29 \mathrm{~mm}$. Moreover, the estimates are much longer than the values obtained by Johnson et al. (1964) who reported mean retention time in wether lambs ranged between 23.2 and $26.1 \mathrm{~h}$. On the other hand, Krause et al. (2002) found that transit time decreased when forage particle size was increased and total mean retention time in the gastrointestinal tract of cows was decreased by increasing forge particle size. These discrepancies in total mean retention time are explained mainly by differences in model and method of calculation, marker specificities, feeding circumstances, particle length of hay, dietary energy and animal species.

There was significant $(\mathrm{p}<0.05)$ effect of feeding frequency on retention times; lambs fed once a day had 4.9 and $3.8 \mathrm{~h}$ longer ruminal and total mean retention time, respectively than those fed twice daily. Nocek and Braund (1985) found that cows fed once daily tended to drink the least amount of water in comparison with those fed more frequently. Similar results were reported by Ulyatt et al. (1984) who found that frequent feeding may increase water consumption and subsequently increased the rate of ingesta removal from the rumen, resulting in less time exposure for microbial fermentation. In this experiment however, it seems that lambs fed twice daily probably tended to increase their water intake which causes increased rate of digesta passage from the rumen. On the other hand, Goetsch and Galyean (1983) and Klusmeyer et al. (1990) reported no effects of feeding frequency on ruminal fluid and particulate outflow in cows. The discrepancies in literatures may be related to the level of DM intake (Owens et al., 1986) and nature of the diets fed (Owens and Goetsch, 1986; Cecava et al., 1990).

Digestibility coefficients: The effects of mean particle length of alfalfa hay on total-tract nutrient digestibility coefficients are shown in Table 2. Digestion coefficients of DM and CP were not affected by particle length of alfalfa hay in the experimental diets. Lack of effect of chopping forages on digestibility of DM and CP has been observed by Hogan and Weston (1967) and Thomson et al. (1972) who did not observe any effect of altering the physical form of the dried alfalfa on the pattern of digestion within the alimentary tract of sheep.

Generally, the obtained values for total-tract digestibility coefficients of ADF and NDF were relatively high considering the type of diets fed in this trial (low fibrous). These results however, agreed well with the findings reported by Krause et al. (2002) for a total mixed ration with a ratio of concentrate to alfalfa of 61:39(DM basis). The digestibility of ADF and NDF were 4.2 and $5.3 \%$ units higher $(\mathrm{p}<0.05)$, respectively for long-hay diet versus $9.5 \mathrm{~mm}$ pelleted-diet whereas no significant differences were noted between 9.5 and $14 \mathrm{~mm}$ diets. Woodford and Murphy (1988) and Hadjigeorgiou et al. (2003) showed reduction in total-tract ADF and NDF digestibility in the rumen of sheep when long alfalfa was ground and pelleted. Depression of ADF and NDF digestibility with chopping and pelleting ( $9.5 \mathrm{~mm}$ diet) was probably attributable to the noted shorter ruminal retention time of the digesta resulting in less time available for microbial digestion in the rumen. In addition, high concentrate feeding has been shown to shift the microbial population, resulting in increased lactate production, depressed rumen $\mathrm{pH}$ and reduced cellulolytic activity (Stewart, 1977). Because cellulolytic activity is sensitive to acidity, it is suggested that the depression in ADF and NDF digestibility noted on 9.5 and $14 \mathrm{~mm}$ pelleted-diets is also associated with the high concentrate diets used in this study, reducing cellulolytic activity due to acidic conditions from rapid grain fermentation. Consequently, dietary pelleted-concentrate with added long hay may have increased the time spent chewing, thereby increasing the volume of saliva produced that acts to buffer ruminal contents and causing a trend toward increased ruminal $\mathrm{pH}$, resulting in improved fiber digestibility (Woodford and Murphy, 1988).

Apparent total tract digestibility of $\mathrm{DM}, \mathrm{CP}$ and $\mathrm{ADF}$ were not affected $(p>0.05)$ by feeding the lambs once or twice daily. The non-significant difference between the feeding frequencies is consistent with the results reported in literature for DM (Drennan et al., 2006) and CP digestibility (Faichney, 1968). In contrast to the former findings, Shabi et al. (1999) reported that DM and CP digestibility were lower when animals fed the daily ration as a single meal than if the ration were fed in two or more portions during the day whereas Bunting et al. (1987) observed that apparent CP digestibility decreased with increasing meal frequency. There was a significant difference $(p<0.05)$ for apparent total tract digestibility of NDF as NDF digestibility decreased in lambs fed pelleted high-concentrate diets twice daily in comparison with those fed once daily. Bunting et al. (1987) and Cecava et al. (1990) found similar result that the percentage of NDF intake digested tended to be lower for feeding frequencies beyond once daily. On the other hand, Ulyatt et al. (1984) concluded that neither the extent nor primary sites of digestion of cell wall components were affected by increasing the frequency of feeding from one to 24 times daily in sheep fed alfalfa hay diet. 


\section{CONCLUSION}

The results of this experiment are interpreted to conclude that offering long alfalfa hay to growing Najdi lambs once daily resulted in noticeable increased in ruminal retention and total mean retention times coincided with increased NDF digestibility coefficients as compared with those lambs fed pelleted (9.5 and $14 \mathrm{~mm}$ ) diets twice daily whereas neither particle length of the hay nor frequency of feeding had affected $(p>0.05)$ the lower tract retention and transit times.

\section{ACKNOWLEDGEMENTS}

The researchers would like to record their thanks to ARASCO for funding this experiment. Also, special thanks are extended to the Deanship of Scientific Research and Agricultural Research Center of King Saud University for support in conducting this study. Researchers acknowledge assistance provided by Dr. H. Mogawer and the rest of the staff at ARASCO, the staff at the Animal Production Experimental Station, King Saud University and Mr. El-Sayed Kordi in particular for caring and feeding the lambs.

\section{REFERENCES}

AOAC, 1995. Official Methods of Analysis. 16th Edn., Association of Official Analytical Chemists, Washington, DC., USA.

Alwash, A.H. and P.C. Thomas, 1971. The effect of the physical form of the diet and the level of feeding on the digestion of dried grass by sheep. J. Sci. Food Agric., 22: 611-615.

Bunting, L.D., M.D. Howard, R.B. Muntifering, K.A. Dawson and J.A. Boling, 1987. Effect of feeding frequency on forage fiber and nitrogen utilization in sheep. J. Anim. Sci., 64: 1170-1177.

Cecava, M.J., N.R. Merchen, L.L. Berger and D.R. Nelson, 1990. Effect of energy level and feeding frequency on site of digestion and postruminal nutrient flows in steers. J. Dairy Sci., 73: 2470-2479.

De Oliveira, D.E., S.R. de Medeiros, L.O. Tedeschi, L.J.M. Aroeira and S.C. da Silva, 2007. Estimating forage intake of lactating dual-purpose cows using chromium oxide and n-alkanes as external markers. Sci. Agric., 64: 103-110.

Dhanoa, M.S., R.C. Siddons, J. France and D.L. Ale, 1985. A multicompartmental model to describe marker excretion patterns in ruminants. Br. J. Nutr., 53: $663-671$.
Drennan, M.J., M. McGee and A.P. Moloney, 2006. The effect of cereal type and feeding frequency on intake, rumen fermentation, digestibility, growth and carcass traits of finishing steers offered a grass silage-based diet. Irish J. Agric. Food Res., 45: 135-147.

Faichney, G.J., 1968. The effect of frequency of feeding on the utilization of roughage diets by sheep. Aust. J. Agric. Res., 19: 813-819.

Goetsch, A.L. and M.L. Galyean, 1983. Influence of feeding frequency on passage of fluid and particulate markers in steers fed a concentrate diet. Can. J. Anim. Sci., 63: 727-730.

Hadjigeorgiou, I.E., I.J. Gordon and J.A. Milne, 2003. Intake, digestion and selection of roughage with different staple lengths by sheep and goats. Small Ruminant Res., 47: 117-132.

Hogan, J.P. and R.H. Weston, 1967. The digestion of chopped and ground roughages by sheep. II. Digestion of nitrogen and some carbohydrate fractions in the stomach and intestines. Aust. J. Agric. Res., 18: 803-819.

Johnson, D.E., W.E. Dinusson and D.W. Bolin, 1964. Rate of passage of chromic oxide and composition of digesta along the alimentary tract of wethers. J. Anim. Sci., 23: 499-505.

Kaske, M. and W. von Engelhardt, 1990. The effect of size and density on mean retention time of particles in the gastrointestinal tract of sheep. Br. J. Nutr., 63: $457-465$.

Klusmeyer, T.H., M.R. Cameron, G.C. McCoy and J.H. Clark, 1990. Effects of feed processing and frequency of feeding on ruminal fermentation, milk production and milk composition. J. Dairy Sci., 73: 3538-3543.

Krause, K.M., D.K. Combs and K.A. Beauchemin, 2002. Effects of forage particle size and grain fermentability in midlactation cows. I. Milk production and diet digestibility. J. Dairy Sci., 85: 1936-1946.

Leonardi, C., K.J. Shinners and L.E. Armentano, 2005. Effect of different dietary geometric mean particle length and particle size distribution of oat silage on feeding behavior and productive performance of dairy cattle. J. Dairy Sci., 88: 698-710.

Liu, X., Z. Wang and F. Lee, 2005. Influence of concentrate level on dry matter intake, $\mathrm{N}$ balance, nutrient digestibility, ruminal outflow rate and nutrient degradability in sheep. Small Rumin. Res., 58: $55-62$.

NRC, 1985. Nutrient Requirements of Domestic Animals No. 6. Nutrient Requirements of Sheep. 6th Edn., National Academy of Science, Washington, DC., USA. 
Nocek, J.E. and D.G. Braund, 1985. Effect of feeding frequency on diurnal dry matter and water consumption, liquid dilution rate and milk yield in first lactation. J. Dairy Sci., 68: 2238-2247.

Owens, F.N. and A.L. Goetsch, 1986. Digesta Passage and Microbial Protein Synthesis. In: Control of Digestion and Metabolism in Ruminants, Miligan, L.P., W.L. Grovum and A. Dobson (Ed.). Prentice-Hall, Englewood Cliffs, NJ., pp: 196.

Owens, F.N., R.A. Zinn and Y.K. Kim, 1986. Limits to starch digestion in the ruminant small intestine. $\mathrm{J}$. Anim. Sci., 63: 1634-1648.

Robles, V., L.A. Gonzalez, A. Ferret, X. Manteca and S. Calsamiglia, 2007. Effects of feeding frequency on intake, ruminal fermentation and feeding behavior in heifers fed high-concentrate diets. J. Anim. Sci., 85: $2538-2547$.

SAS, 1998. User's Guide Statistics. Version 7, SAS Institute Inc., Cary, NC.

Shabi, Z., I. Bruckental, S. Zamwell, H. Tagari and A. Arieli, 1999. Effects of extrusion of grain and feeding frequency on rumen fermentation, nutrient digestibility and milk yield and composition in dairy cows. J. Dairy Sci., 82: 1252-1260.

Shaver, R.D., A.J. Nytes, L.D. Satter and N.A. Jorgensen, 1986. Influence of amount of feed intake and forage physical form on digestion and passage of prebloom alfalfa hay in dairy cows. J. Dairy Sci., 69: 1545-1559.
Stewart, C.S., 1977. Factors affecting the cellulolytic activity of rumen contents. Applied Environ. Microbiol., 33: 497-502.

Thomson, D.J., D.E. Beever, J.F.C. da Silva and D.G. Armstrong, 1972. The effect in sheep of physical form on the sites of digestion of a dried lucerne diet. Br. J. Nutr., 28: 31-41.

Ulyatt, M.J., G.C. Waghorn, A. John, C.S.W. Reid and J. Monro, 1984. Effect of intake and feeding frequency on feeding behavior and quantitative aspects of digestion in sheep fed chaffed Lucerne hay. J. Agric. Sci., 102: 645-651.

Utley, P.R., J.A. Boling, N.W. Bradley and R.E. Tucker, 1970. Recovery of radioactive chromic oxide from the bovine gastrointestinal tract. J. Nutr., 100: 1227-1231.

Van Soest, P.J., J.B. Robertson and B.A. Lewis, 1991. Methods for dietary fiber, neutral detergent fiber and nonstarch polysaccharides in relation to animal nutrition. J. Dairy Sci., 74: 3583-3597.

Welch, J.G., 1982. Rumination, particle size and passage from the rumen. J. Anim. Sci., 54: 885-894.

Woodford, S.T. and M.R. Murphy, 1988. Effect of forage physical form on chewing activity, dry matter intake and rumen function of dairy cows in early lactation. J. Dairy Sci., 71: 674-678. 